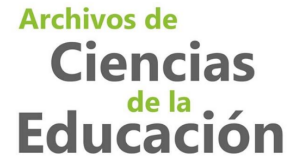

Archivos de Ciencias de la Educación ISSN: 2346-8866

revistaarchivos@fahce.unlp.edu.ar

Universidad Nacional de La Plata Argentina

\title{
Introducción al dossier: A 50 años de Pedagogía del Oprimido: lecturas en torno al legado de Paulo Freire
}

\author{
Brugaletta, Federico \\ Introducción al dossier: A 50 años de Pedagogía del Oprimido: lecturas en torno al legado de Paulo Freire \\ Archivos de Ciencias de la Educación, vol. 13, núm. 16, 2019 \\ Universidad Nacional de La Plata, Argentina \\ DOI: https://doi.org/10.24215/23468866e065
}

Atribución no comercial compartir igual (CC BY-NC-SA) 4.0 
Dossier: A 50 años de Pedagogía del Oprimido: lecturas en torno al legado de Paulo Freire Introducción al dossier: A 50 años de Pedagogía del Oprimido: lecturas en torno al
legado de Paulo Freire

Federico Brugaletta

DOI: https://doi.org/10.24215/23468866e065

Universidad Nacional de La Plata, Argentina

fbrugaletta@fahce.unlp.edu.ar

La pedagogía de Paulo Freire constituye en la actualidad una firme referencia para muchos/as educadores/as en el despliegue de prácticas educativas asociadas a horizontes de inclusión y justicia social. Desde sus planteos iniciales en la década del sesenta, los saberes y las prácticas educativas promovidas por el pedagogo brasileño se diseminaron en múltiples contextos y experiencias no solo en el campo de la alfabetización de adultos/as sino también en las militancias de organizaciones sociales y políticas, en las iniciativas de estudiantes y profesores en tareas de extensión universitaria o en el accionar de los/as docentes por formas más democráticas de habitar las instituciones en distintos niveles del sistema educativo.

En el año 2020, se cumplen cincuenta años de la primera edición en formato de libro de Pedagogía del oprimido, el título más reconocido de Paulo Freire no solo en América Latina sino a escala mundial. Texto producido durante el exilio chileno del pedagogo, fue publicado por primera vez en 1970 en dos idiomas: en castellano por la editorial Tierra Nueva en Montevideo y en inglés por la editorial Herder \& Herder de Nueva York. Desde un principio la obra trascendió tempranamente las fronteras de América Latina y su circulación se constató con ediciones en Italia, Alemania, Portugal, Inglaterra, Indonesia, Dinamarca, Francia y Japón, entre otros países.

La historia temprana de este libro estuvo asociada a las apuestas de transformación social de educadores/ as, militantes y organizaciones políticas de inicios de la década del setenta y, por lo tanto, fue objeto de censura ideológica durante las dictaduras del Cono Sur. La apertura democrática a partir de mediados de los años ochenta posibilitó una nueva circulación de la obra de Freire, aunque también se produjeron silenciamientos y objeciones que deslegitimaban su pensamiento como algo del pasado que ya no tenía vigencia. Sin embargo, en la década pasada, gobiernos populares de América Latina recuperaron el legado de Freire en el marco políticas educativas orientadas a la inclusión social, al igual que muchas editoriales de mundo entero siguieron produciendo constantes rediciones y traducciones, convirtiendo al pedagogo en una de las figuras intelectuales latinoamericanas más citadas en el mundo entero en la actualidad.

El objetivo del presente dossier es ofrecer a los/as lectores/as de Archivos de Ciencias de la Educación un conjunto de reflexiones que permitan comprender y problematizar tanto la historia de la obra y las ideas que ella condensó en el pasado reciente, así como también la permanencia de su legado para pensar el presente de la educación en un horizonte de justicia social. Los artículos que componen el presente dossier aportan novedosos análisis sobre la pedagogía freireana desde distintas disciplinas como la historia de la pedagogía, la filosofía y la política educativa que se suman a un conjunto importante de reflexiones que se están desarrollando en varias latitudes a propósito de la conmemoración de los cincuenta años de la publicación de Pedagogía del oprimido y de los cien años del natalicio de Paulo Freire.

El primer artículo, "Pedagogía del oprimido. Una obra cincuentenaria en evolución” escrito por José Eustáquio Romão y Natatcha Priscilla Romão, ambos de la Universidade Nove de Julho de São Paulo (Brasil), analiza la génesis de Pedagogía del oprimido considerando tanto el proceso de escritura de la obra entre 1967 y 1968 como las ediciones que permitieron su circulación a nivel internacional a inicios de los años setenta. 
En primer lugar, el artículo expone las particulares circunstancias en las que Paulo Freire produjo el texto de Pedagogía del oprimido durante su exilio chileno así como también su particular forma de escribir con otros en una trama de pensamiento transindividual. En segundo lugar, focaliza en el proceso de edición, destacando particularmente las vicisitudes de la publicación del libro en el contexto de la dictadura brasileña explicitando la ausencia de los diagramas sobre "teoría de la acción evolucionaria" en las ediciones lusófonas como una forma de "disfrazar" el carácter revolucionario de la obra frente a los censores. Finalmente, el artículo destaca la relevancia de la reedición del manuscrito original de Pedagogía del oprimido, aquel que el pedagogo diagramó a mano especialmente como regalo para su anfitrión chileno Jacques Chonchol. La posibilidad de contar con este manuscrito abre un prometedor panorama para el desarrollo de investigaciones comparadas entre el manuscrito y las distintas ediciones posteriores de la obra.

El segundo artículo, "La idea de revolución en Pedagogía del Oprimido" escrito por Inés Fernández Mouján, integrante de la Cátedra Abierta Paulo Freire de la Universidad Nacional de Mar del Plata, estudia la noción de "revolución" en esta obra cincuentenaria. El artículo no solo repone el contexto de producción y las diferencias entre las distintas ediciones de Pedagogía del oprimido, sino que se adentra en su interior conceptual para poner de manifiesto las preocupaciones intelectuales y políticas del pedagogo en diálogo con los problemas de su tiempo. La autora realiza un ejercicio muy riguroso de comparación entre versiones manuscritas y publicadas de las obra lo que le permite encontrar omisiones significativas, así como profundizar asociaciones que Freire articuló entre "revolución” y "pedagogía”. El artículo tiene la virtud de ubicar estas reflexiones de Paulo Freire en su propio tiempo: el de los debates intelectuales y políticos que atravesaban a movimientos populares y de izquierda en el contexto de apuestas políticas por la liberación de los pueblos de América Latina. Asimismo, pone de relevancia la trama de diálogos intelectuales que Freire tejió con distintas tradiciones filosóficas como el existencialismo, la fenomenología y el marxismo. Fernández Mouján destaca diálogos poco reconocidos, aquel que Freire estableció con el pensamiento descolonial de Frantz Fanon y Albert Memmi, como con la crítica de Rosa de Luxemburgo a las vanguardias de izquierda dogmáticas. Problemas tales como la conceptualización de la violencia, la relación entre líder y masa y el carácter pedagógico de la revolución son tratados con exhaustividad y además de modo contextualizado señalando los lectores de época que Freire buscaba interpelar con sus ideas: líderes políticos, cuadros militantes, hombres y mujeres del pueblo en la lucha por la liberación. Finalmente, la autora remarca la significación de la obra más allá de su propia época, un legado de pensamiento aún vigente para pensar las nuevas formas de colonialidad y una pedagogía capaz de transformarlas.

"Paulo Freire y la Igualdad" es el título del tercer artículo escrito por Walter Kohan, profesor de la Universidade do Estado do Rio de Janeiro (Brasil), cuyo objetivo es dilucidar el sentido filosófico de la igualdad en el pensamiento freireano. En primer lugar, desmenuza lógicamente el axioma "nadie es superior a nadie" a partir de cual Paulo Freire afirmaba la igualdad como punto de partida para la construcción de una igualdad social remarcando un desfase entre el plano epistemológico y el político. En segundo lugar, el autor desarrolla, a partir de los postulados freireanos, el desafío que supone pensar la igualdad como un principio dentro y fuera de las instituciones educativas. De allí su apuesta por enunciar y vivir la igualdad en las prácticas pedagógicas como parte de una política para la educación que adquiere especial sentido en sociedades desiguales como las nuestras. En tercer lugar, el autor contrasta los sentidos sobre la igualdad presentes en el pensamiento freireano con aquellos postulados por el pedagogo francés del siglo XIX Joseph Jacotot. Allí conecta una tradición del pensamiento ilustrado decimonónico que postuló la fe en la igualdad de las inteligencias con el axioma freireano "nadie educa a nadie" presente en Pedagogía del oprimido. Inspirado por ambos pedagogos en una especie de cadena histórica, Kohan afirma la necesidad de una concepción igualitaria de la capacidad de pensar de los sujetos de la educación como condición política para desplegar la potencia problematizadora del mundo en que se vive sin un contenido ontológicamente prefijado.

El cuarto artículo titulado "Freire en Finlandia: trayectorias de la presencia de Paulo Freire en el Norte global" fue escrito por Juha Suoranta y Tuukka Tomperi, docentes e investigadores de la Universidad 
de Tampere en Finlandia y traducido del inglés al castellano para este dossier por Amparo Tirado y Sol Maluendez, estudiantes de la carrera de Ciencias de la Educación de la Universidad Nacional de La Plata. El artículo analiza las trayectorias de recepción de la pedagogía de Paulo Freire en el país nórdico desde fines de la década del sesenta hasta la actualidad señalando el interés que el pensamiento latinoamericano había despertado en sectores progresistas no solo respecto al campo de la pedagogía sino también al de la música, la literatura y la asistencia a los exiliados. Los autores dan cuenta de modo exhaustivo de las distintas iniciativas que articularon la pedagogía freireana a experiencias de alfabetización de adultos, formación de trabajadores o círculos de cultura en cárceles, así como también más recientemente a la formación docente. Destacan asimismo la afinidad entre la pedagogía de Paulo Freire y la reforma del sistema educativo finlandés a fines de los años sesenta en tanto compartían un discurso en favor de la justicia social en ámbito educativo. Al respecto de Pedagogía del oprimido los autores reflexionan sobre los procesos de traducción permitieron que dicha obra se conociera en Finlandia, primero a través de su versión en inglés y luego en 2006 en finés gracias a la labor de uno de los autores del artículo.

Finalmente, el dossier se completa con la conferencia inaugural de la Cátedra Libre Paulo Freire de la UNLP a cargo de la Dra. Adriana Puiggrós, realizada el 23 de mayo de año 2019 en el aula más grande de la Facultad de Humanidades y Ciencias de la Educación que rebalsaba de oyentes. Agradecemos a María Aprigliano y Sabrina Larocca, estudiantes de la carrera de Ciencias de la Educación, por su colaboración en la desgrabación del audio de esta conferencia y a la Cátedra Libre Paulo Freire de la UNLP por la posibilidad compartir las reflexiones de esta destacada pedagoga argentina. Este texto es acompañado por una nota introductoria realizada por Mónica Fernández Pais - profesora de nuestra universidad e integrante de la mencionada cátedra libre- quién ofrece a los/as lectores/as un excelente material para explorar el extenso vínculo de pensamiento que Adriana Puiggrós estableció con las ideas de Paulo Freire.

En síntesis, los textos presentes en el dossier ofrecen la posibilidad de revisitar el pensamiento de Paulo Freire y, en particular, la obra de Pedagogía del oprimido, a partir de distintos ángulos e interrogantes. Desde la historia de la producción y circulación editorial del libro hasta la batallas por las ideas y prácticas políticas que Paulo Freire en tanto intelectual de época estaba librando. Desde la vigencia de su pensamiento para recrear una política para la educación en la actualidad América Latina hasta la recepción sus ideas en países del Norte global que identifican a Paulo Freire como un referente para la formación docente. A cincuenta años de la edición de Pedagogía del oprimido esperamos que este dossier incite nuevas lecturas del legado del pedagogo pernambucano.

\section{BY-NC-SA}

